\title{
Double U-Shaped Slots Loaded Stacked Patch Antenna for Multiband Operation
}

\author{
Nagendra Prasad Yadav \\ School of Electronic Engineering and Optoelectronic Technology, Nanjing University of Science and Technology, \\ Nanjing, China \\ Email: nagendra1nagendra@gmail.com
}

Received 13 August 2015; accepted 6 September 2015; published 9 September 2015

Copyright (c) 2015 by author and Scientific Research Publishing Inc.

This work is licensed under the Creative Commons Attribution International License (CC BY). http://creativecommons.org/licenses/by/4.0/

(c) () Open Access

\section{Abstract}

The design of a seven-band stacked patch antenna for the $\mathrm{C}, \mathrm{X}$ and $\mathrm{Ku}$ band is presented. The antenna consists of an H-slot loaded fed patch, stacked with dual U-slot loaded rectangular patch to generate the seven frequency bands. The total size of the antenna is $39.25 \times 29.25 \mathrm{~mm}^{2}$. The multiband stacked patch antenna is studied and designed using IE3D simulator. For verification of simulation results, the antenna is analyzed by circuit theory concept. The simulated return loss, radiation pattern and gain are presented. Simulated results show that the antenna can be designed to cover the frequency bands from (4.24 GHz to $4.50 \mathrm{GHz}, 5.02 \mathrm{GHz}$ to $5.25 \mathrm{GHz})$ in $\mathrm{C}$-band application, (7.84 GHz to 8.23 GHz) in X-band and (12.16 GHz to $12.35 \mathrm{GHz}, 14.25 \mathrm{GHz}$ to $14.76 \mathrm{GHz}$, 15.25 GHz to $15.51 \mathrm{GHz}, 17.52 \mathrm{GHz}$ to $17.86 \mathrm{GHz}$ ) in $\mathrm{Ku}$ band applications. The bandwidths of each band of the proposed antenna are 5.9\%, 4.5\%, 4.83\%, 2.36\%, 3.53\%, 1.68\% and 1.91\%. Similarly the gains of the proposed band are $2.80 \mathrm{dBi}, 4.39 \mathrm{dBi}, 4.54 \mathrm{dBi}, 10.26 \mathrm{dBi}, 8.36 \mathrm{dBi}$ and $9.91 \mathrm{dBi}$, respectively.

\section{Keywords}

H-Shape Fed Patch, Microstrip Patch Antenna, Double U-Shape Slot Loaded Stacked Patch, Multiband Antenna

\section{Introduction}

Antenna is a very important component of communication system. The enormous growth of mobile and satellite communication systems along with wonderful use of radars opens a huge demand to new kind of antennas such as small antennas, multi frequency antennas, and broadband antennas [1]-[3]. Planar multi-resonators and stacked microstrip patch antenna techniques are combined to yield a wide bandwidth and higher gain. Several two-layered 
configurations have been discussed in [4]-[6], in which only a single patch on the bottom layer is fed by a coaxial probe and second patch on the top layer and both are electromagnetically coupled to each other. Multi-band or reconfigurable antennas are suitable candidates for providing multi-functionality. This will result in significant reductions in antenna size and cost. The primary advantage of the proposed multiband antenna lies in its ability to support two separate applications at two different frequency bands with distinctly different radiation patterns, gain and polarization characteristics using a single radiating aperture [7]. Although multi-band antennas have the capability of serving multiple frequency bands with one antenna, they are considered a weak choice in comparison to reconfigurable antennas because of crosstalk from the neighbor bands. In [8], we have to see that the multiband antenna can be obtained by using of slot couple technique in multiple patches. In 2012, M. A. Motin, et al. [9], presented the multiband microstrip patch antenna for X, K and Ku band application. In 2014, Jianxing Li et al. [10], represented the multiband probe-fed stacked patch antenna for GNSS application.

In the present paper, a multiband microstrip stacked patch antenna is introduced. The proposed structure is a planar structure having all the dimensions in $\mathrm{mm}$. The proposed antenna is designed by using a substrate of FR4 having thickness $1.6 \mathrm{~mm}$. This proposed antenna is having seven bands of operation. The entire investigation is based on equivalent circuit model. In [11], it represents the multi-band antenna by using stacked patch with multislot loaded patch, which can be compared to the proposed design. The co-axial feed technique is used for the analysis of this antenna because it occupies less space and has low spurious radiation by using Teflon connector. The proposed antenna design can be used in mobile communication, radar and satellite communication. Details of the antenna are given in the next stage.

\section{Antenna Design and Theoretical Considerations}

The design of the proposed multiband antenna is depicted in Figure 1. The upper patch is double U-shaped slot loaded stacked patch and the lower patch is the H-slot loaded fed patch. Due to the presence of the stacked patch antenna, there are two resonances associated with the two resonators [12].

Microstrip patch with a dielectric cover is considered as a single patch with a semi-infinite superstore with relative permittivity equal to unity and the single relative dielectric constant $\left(\varepsilon_{k}\right)$ given as:

$$
\varepsilon_{k}=\frac{2 \varepsilon_{\text {eff }}-1+p}{1+p}
$$

where

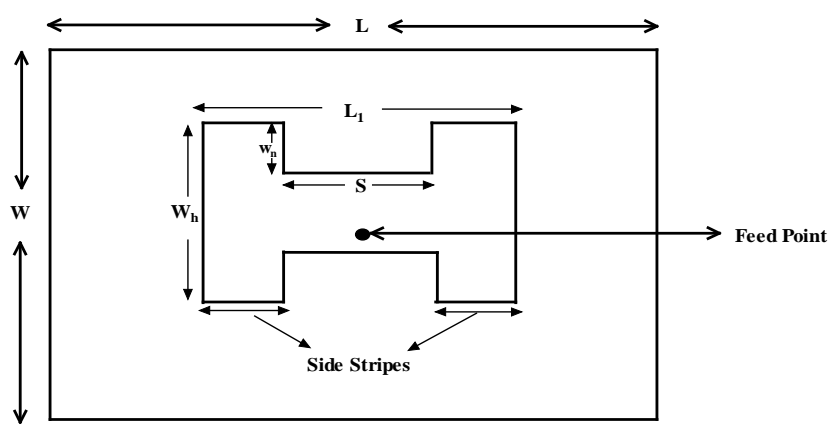

(a)

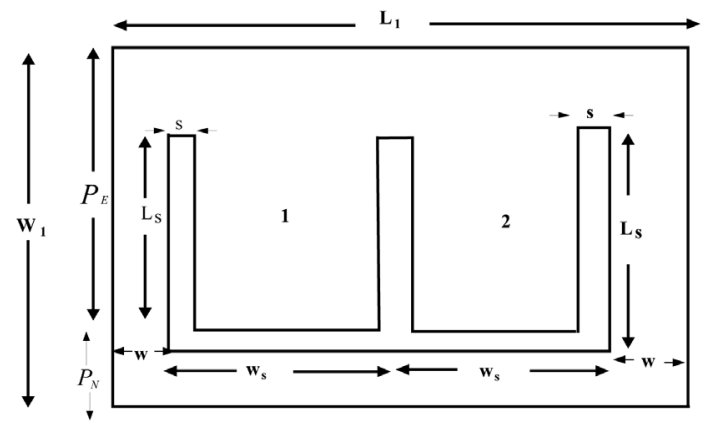

(b)

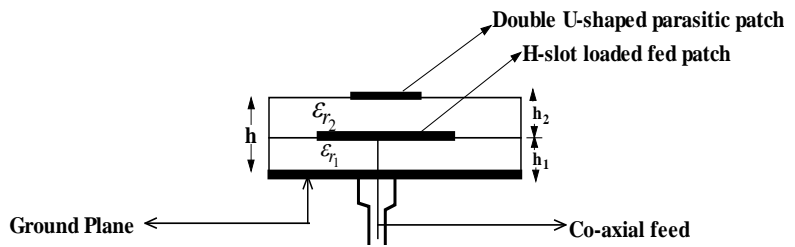

(c)

Figure 1. Configuration of stacked patch antenna. (a) H-slot loaded fed patch; (b) Double U-shaped slots loaded parasitic patch; (c) Side view of the proposed antenna. 


$$
p=1+\frac{10 h_{1}}{W_{e}}
$$

in which $W_{e}$ is the effective width and $\varepsilon_{\text {eff }}$ is the effective dielectric constant of the structure [13]. The effective dielectric constant of the lower patch is given as

$$
\varepsilon_{e_{1}}=\frac{\varepsilon_{k}+1}{2}+\frac{\varepsilon_{k}+1}{2}\left(1+\frac{12 h_{1}}{W}\right)
$$

where,

$h_{1}=$ height between ground plane and lower patch;

$W=$ width of the patch.

The equivalent circuit of the simple patch antenna is parallel combination of resistance $\left(R_{1}\right)$, inductance $\left(L_{1}\right)$ and capacitance $\left(C_{1}\right)$ (Figure 2), whose values are defined as [14]

$$
\begin{gathered}
C_{1}=\frac{\varepsilon_{0} \varepsilon_{e_{1}} L W}{2 h_{1}} \cos ^{-2}\left(\frac{\pi y_{0}}{L}\right) \\
L_{1}=\frac{1}{\omega_{1}^{2} C_{1}} \\
R_{1}=\frac{Q_{1}}{\omega_{1} C_{1}}
\end{gathered}
$$

where

$$
Q_{1}=\frac{c \sqrt{\varepsilon_{e_{1}}}}{4 f_{1} h_{1}}
$$

$L=$ length of the lower patch;

$y_{o}=$ Y-coordinate of the feed point.

$$
\begin{gathered}
\omega_{1}=2 \pi f_{1} \\
f_{1}=\frac{c}{2(L+2 \Delta L) \sqrt{\varepsilon_{\text {eff }}}}
\end{gathered}
$$

$c=$ velocity of light.

$\Delta L=$ fringing length for the lower patch.

Considering the top patch as a simple stacked rectangular microstrip patch, the values of resistance $\left(R_{2}\right)$, inductance $\left(L_{2}\right)$ and capacitance $\left(C_{2}\right)$ can be given as

$$
\begin{aligned}
C_{2} & =\frac{\varepsilon_{0} \varepsilon_{r_{2}} L_{2} W_{2}}{2 h_{2}} \\
L_{2} & =\frac{1}{\omega_{2}^{2} C_{2}} \\
R_{2} & =\frac{Q_{2}}{\omega_{2} C_{2}}
\end{aligned}
$$

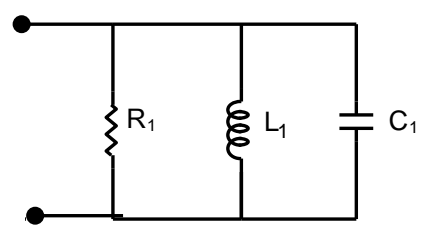

Figure 2. Equivalent circuit of patch antenna. 
where

$$
Q_{2}=\frac{c \sqrt{\varepsilon_{e_{2}}}}{4 f_{2} h_{2}}
$$

where

$L_{2}=$ length of the stacked patch;

$W_{2}=$ width of the stacked patch;

$\omega_{2}=2 \pi f_{2}$;

$$
f_{2}=\frac{c}{2\left(L_{2}+2 \Delta L_{2}\right) \sqrt{\varepsilon_{e_{2}}}}
$$

$\Delta L_{2}=$ fringing length for the top patch.

The equivalent circuit of the fed patch is shown in Figure 3(a), in which $\Delta L_{1}$ and $\Delta C_{1}$ are the additional inductance and capacitance respectively, which originate due to introducing the two notches and $R_{H}$ is resonance resistance after cutting the notches into the patch. The value of $R_{H}$ can be calculated using Equation (7) and the $\Delta L_{1}, \Delta C_{1}$ can be given as [15]

$$
\Delta L_{1}=\frac{h_{1} \mu_{0} \pi}{8}\left(\frac{W_{h}}{w_{n}}\right)
$$

where

and

$$
\mu_{0}=4 \pi 10^{-7} \mathrm{H} / \mathrm{m}
$$

$$
\Delta C_{1}=\left(\frac{W_{h}}{w_{n}}\right) C_{s}
$$

where $C_{s}$ is the gap capacitance between two side strips [16]. Now the equivalent circuit of H-shaped patch is given as shown in Figure 3(b) in which " $Z_{N}$ " is the impedance of the notch incorporated patch and is calculated from Figure 3(a), $Z_{P}$ is the impedance of the initial patch and $C_{m}$ and $L_{m}$ are the capacitive and inductive coupling between two resonant circuits.

When a dual U-slots is cut into the stacked patch, current distribution changes which ultimately changes the resonance behavior of the patch. Due to this changing in the patch adds series inductance $\left(\Delta L_{2}\right)$ and series capacitance ( $\Delta C_{2}$ ) in the initial circuit of the stacked patch, which is shown in Figure 4, in which the resonance resistance $R_{2}, \Delta L_{2}$ and $\Delta C_{2}$ are given as [17]-[19]

$$
R_{2}=\frac{Q_{2} h_{2}}{\pi f_{r} \varepsilon_{\text {eff }} \varepsilon_{0} W_{2} L_{2}} \cos ^{2}\left(\left(\left(\frac{\pi y_{0}}{L_{\text {eff }}}\right)\right)\right)
$$

where $\ell_{\text {eff } 2}$ is the effective length [15] and can be given as

$$
L_{\text {eff } 2}=L_{2}+\left(\sin \left(\pi w / L_{2}\right)\right) \frac{L_{s}}{2}
$$

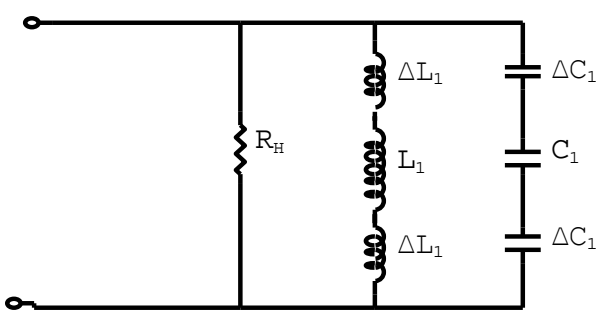

(a)

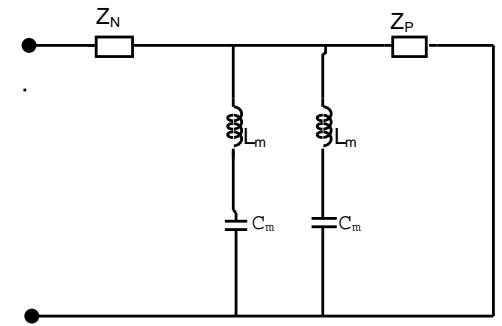

(b)

Figure 3. (a) Equivalent circuit of RMSA due to notch effect; (b) Equivalent circuit of $\mathrm{H}$ shaped fed patch. 


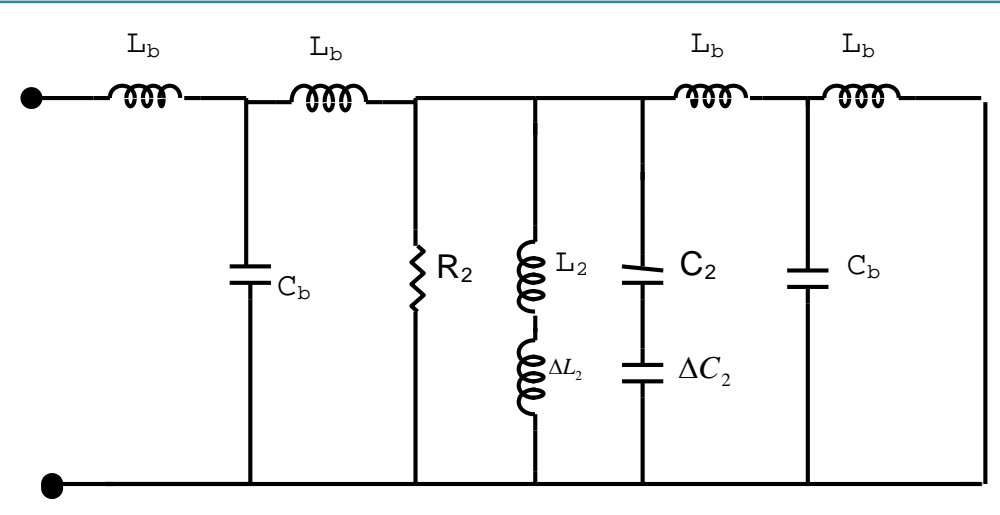

Figure 4. Equivalent circuit of U-slot loaded patch.

$$
\Delta L_{2}=\frac{Z_{1}+Z_{2}}{16 \pi f_{1} \cos ^{-2}\left(\frac{\pi y_{0}}{P_{E}}\right)} \tan \left(\frac{\pi f_{1} L_{s}}{c}\right)
$$

where

$$
\begin{aligned}
& P_{E}=W_{1}-P_{N} ; \\
& Z_{1}=\frac{120 \pi}{\frac{w_{s}}{h_{2}}+1.393+0.667 \log \left(\frac{w_{s}}{h_{2}}+1.44\right)} ; \\
& Z_{2}=\frac{120 \pi}{\frac{w_{s}-2 s}{h_{2}}+1.393+0.667 \log \left(\frac{W_{s}-2 s}{h_{2}}+1.44\right)}
\end{aligned}
$$

$\Delta C_{2}$ is calculated as gap capacitance and given by [18].

The value of $C_{b}$ and $L_{b}$ are calculated as [19]

$$
\begin{aligned}
& \frac{C_{b}}{w}=\left(9.5 \varepsilon_{r_{2}}+1.25\right) \frac{w}{h_{2}}+5.2 \varepsilon_{r_{2}}+7.0 \mathrm{PF} / \mathrm{m} \\
& \frac{2 L_{b}}{h_{2}}=100\left(4 \frac{w}{h_{2}}-4.21\right) \mathrm{NH} / \mathrm{m}
\end{aligned}
$$

Similarly we can analyze circuit concept of second U-slot which is parallel and compact to first U-slot on the upper patch.

The equivalent circuit of the proposed multiband antenna can be given as shown in Figure 5, in which only capacitive coupling is considered and given as [20]

$$
C_{m}^{\prime}=\frac{\left(C_{e q}+C_{e q}^{\prime}\right)+\sqrt{\left(C_{e q}+C_{e q}^{\prime}\right)^{2}-4 C_{e q} C_{e q}^{\prime}\left(1-k_{c}^{-2}\right)}}{2}
$$

where

$$
\begin{gathered}
C_{e q}=\frac{\Delta C_{1} C_{p}}{2 C_{p}+\Delta C_{1}} \\
C_{e q}^{\prime}=\frac{\Delta C_{2} C_{2}}{2 C_{2}+\Delta C_{2}}
\end{gathered}
$$

and $k_{c}$ is the coupling coefficient between two resonators.

Thus the total input impedance can be calculated from Figure 5 as 


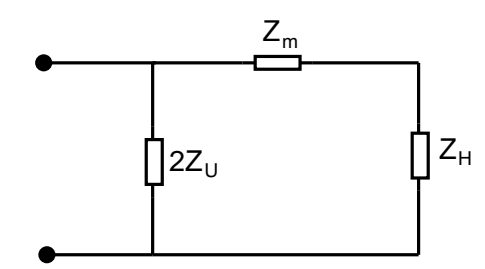

Figure 5. Equivalent circuit of proposed stacked patch antenna.

$$
Z_{\text {in }}=\frac{2 Z_{U}\left(Z_{m}+Z_{H}\right)}{2 Z_{U}+Z_{H}+Z_{m}}
$$

In which $Z_{H}$ and $Z_{U}$ are the impedances of initial and parasitic patches calculated from Figure 3(b) and Figure 4 respectively and $Z_{m}$ is the impedance due to mutual coupling between fed patch and stacked patch.

\section{Design Specifications for the Proposed Antenna}

\begin{tabular}{ll}
\hline Substrate material used & FR4 \\
Dielectric constant $\left(\varepsilon_{r_{1}}, \varepsilon_{r_{2}}\right)$ & 4.4 \\
Thickness between ground and lower patch $\left(h_{1}\right)$ & $1.6 \mathrm{~mm}$ \\
Thickness between lower and parasitic patch $\left(h_{2}\right)$ & $1.6 \mathrm{~mm}$ \\
Length of the fed patch $(L)$ & $39.25 \mathrm{~mm}$ \\
Width of the fed patch $(W)$ & $29.25 \mathrm{~mm}$ \\
Depth of the notch $\left(w_{n}\right)$ & $4 \mathrm{~mm}$ \\
Width of the notch $(S)$ & $15 \mathrm{~mm}$ \\
Length of the first $U$ slot $\left(L_{s}\right)$ & $15.7 \mathrm{~mm}$ \\
Width of the first U slot $(s)$ & $1.0 \mathrm{~mm}$ \\
Base width of first U-slot $\left(w_{s}\right)$ & $10.3 \mathrm{~mm}$ \\
Length of the second $U$ slot $\left(L_{s}\right)$ & $15.7 \mathrm{~mm}$ \\
Width of the second U slot $(s)$ & $1.0 \mathrm{~mm}$ \\
Base width of second U-slot $\left(w_{s}\right)$ & $10.3 \mathrm{~mm}$ \\
Feed location $\left(x_{0}, y_{0}\right)$ & $(-0.275,-4.37 \mathrm{~mm})$ \\
Length of the parasitic patch $\left(L_{2}\right)$ & $39.25 \mathrm{~mm}$ \\
Width of the parasitic patch $\left(W_{2}\right)$ & $29.25 \mathrm{~mm}$ \\
\hline
\end{tabular}

\section{Discussion of Results}

All the simulation results of the proposed antenna are given as Figures 6-8. Discussion of results have been explain in terms of $S_{11}$ parameters, resonance frequencies, gains and radiation patterns.

The variation of reflection coefficient with frequency for the proposed multiband antenna is depicted in Figure 6; it is found that the antenna can be operated for seven band applications. In which both lower and upper resonance frequencies of each bands are $(4.24 \mathrm{GHz}$ and $4.50 \mathrm{GHz}),(5.02 \mathrm{GHz}$ and $5.25 \mathrm{GHz}),(7.84 \mathrm{GHz}$ and 8.23 GHz), (12.16 GHz and $12.35 \mathrm{GHz}),(14.25 \mathrm{GHz}$ and $14.76 \mathrm{GHz}),(15.25 \mathrm{GHz}$ and $15.51 \mathrm{GHz}),(17.52 \mathrm{GHz}$ and 17.86 GHz) with return loss $-13.81 \mathrm{~dB},-17.02 \mathrm{~dB},-26.07 \mathrm{~dB},-12.79 \mathrm{~dB},-20.42 \mathrm{~dB},-31.32 \mathrm{~dB}$ and $-18.41 \mathrm{~dB}$ respectively. The bandwidth of each bands are $6 \%, 4.5 \%, 4.83 \%, 2.36 \%, 3.53 \%, 1.68 \%$ and $1.91 \%$. From Figure 7, it is observed that proposed antenna gains are $2.80 \mathrm{dBi}, 4.39 \mathrm{dBi}, 4.54 \mathrm{dBi}, 6.25 \mathrm{dBi}, 10.26 \mathrm{dBi}$, $8.36 \mathrm{dBi}$ and $9.91 \mathrm{dBi}$ respectively. From both the figure it is clear that the antenna gain is high as a higher frequency of the proposed antenna so that it is very useful in radar application. In [4], Ansari et al. has already presented the similar work for dual band application. But in the proposed antenna we have replace and changed the radiating patch in place of U-slot loaded patch and H-slot loaded parasitic patch. We have to see that, if changed 


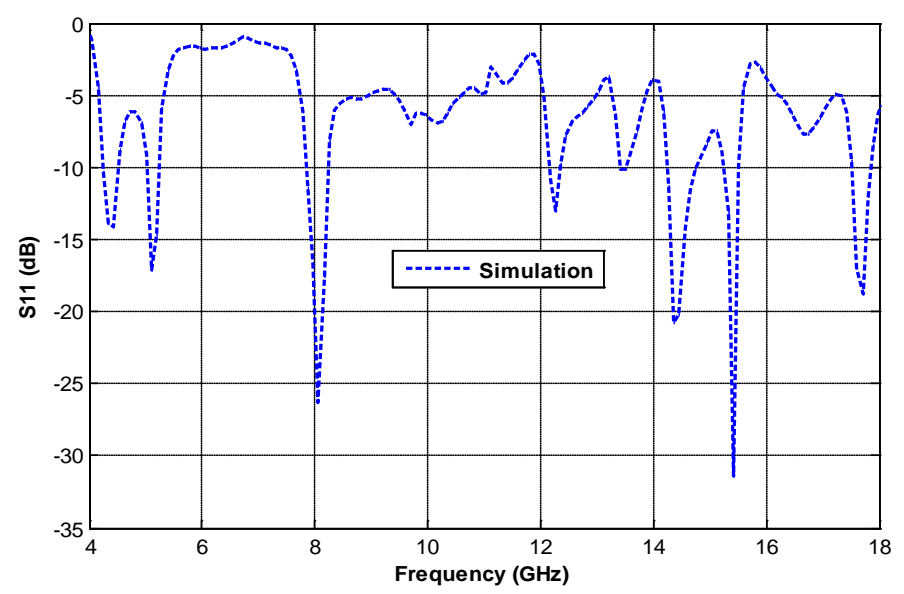

Figure 6. Variation of return loss with frequency for the proposed antenna.

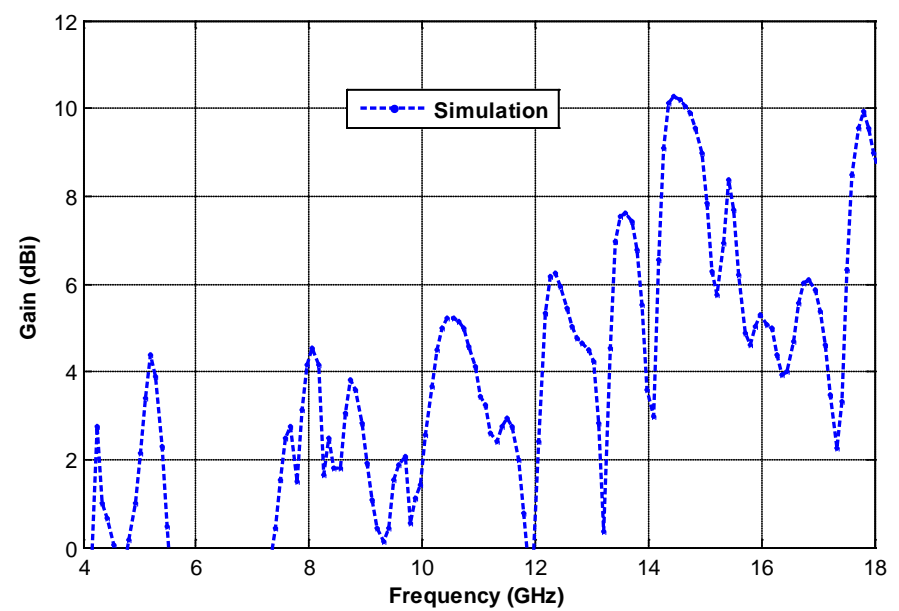

Figure 7. Variation of gain with frequency for the proposed antenna.

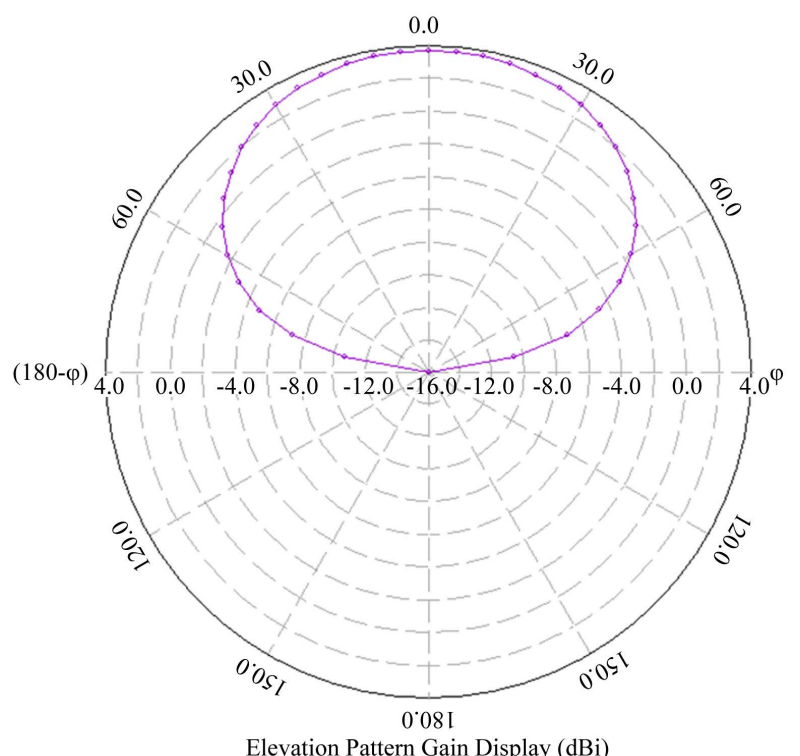

Figure 8. Radiation pattern of the proposed antenna at frequency $8.08 \mathrm{GHz}$. 
the patch, the results are obtained as a multiband antenna with good gain, which is more useful as compared to dual band application presented in 2008. Radiation pattern of the proposed antenna is shown in Figure 8. It is found that radiated power is good. This shows that the directivity improves by stacking dual U-shaped patch.

\section{Conclusion}

A stacked multiband proximity coupled microstrip patch antenna is presented. This antenna has a very simple structure printed on FR4 substrate. Multiband has achieved by using dual U-slot loaded stacked patch. The total volume of the antenna is $39.25 \times 29.25 \times 1.6 \mathrm{~mm}^{2}$. The proposed antenna shows satisfactory multiband performance and good radiation pattern. Proposed antenna finds the application in C, X and Ku band which can be used for radar, VSAT, mobile and satellite communication.

\section{References}

[1] Lee, K.F., Lung, S., Yang, S. and Kishk, A.A. (2008) Dual- and Multiband U-Slot Patch Antennas. IEEE Antennas and Wireless Propagation Letters, 7, 645-647. http://dx.doi.org/10.1109/LAWP.2008.2010342

[2] Ansari, J.A., Yadav, N., Singh, P. and Mishra, A. (2009) Compact Half U Slot Loaded Shorted Rectangular Patch Antenna for Broadband Operation. Progress in Electromagnetic Research M, 9, 215-226. http://dx.doi.org/10.2528/PIERM09090102

[3] Ansari, J.A., Mishra, A., Yadav, N., Singh, P. and Vishvakarma, B.R. (2012) Analysis of W-Slot Loaded Patch Antenna for Dual-Band Operation. International Journal of Electronics, 66, 32-38. http://dx.doi.org/10.1016/j.aeue.2011.04.011

[4] Ansari, J.A., Singh, P., Dubey, S.K., Khan, R.U. and Vishvakarma, B.R. (2008) H-Shaped Stacked Patch Antenna for Dual Band Operation. Progress in Electromagnetic Research B, 5, 291-302. http://dx.doi.org/10.2528/PIERB08031203

[5] Dahele, J.S., Lee, K.F. and Wond, D.P. (1987) Dual Frequency Stacked Annular Ring Microstrip Antenna. IEEE Transactions on Antennas and Propagation, 35, 1281-1285. http://dx.doi.org/10.1109/TAP.1987.1143997

[6] Kumar, G. and Ray, K.P. (2011) Stacked Gap-Coupled Multiresonator Rectangular Microstrip Antennas. IEEE AP-S International Symposium Digest, Boston, 514-517.

[7] Motin, M.A., Hasan, M.I., Habib, M.S. and Sheikh, M.R.I. (2013) Design of a Modified Rectangular Patch Antenna for Quad Band Application. International Conference on Informatics, Electronics \& Vision (ICIEV), Dhaka, 17-18 May 2013, 1-4. http://dx.doi.org/10.1109/iciev.2013.6572671

[8] Ryu, H.-C., Ahn, H.-R., Lee, S.-H. and Park, W.S. (2002) Triple-Stacked Microstrip Patch Antenna for Multiband System. Electronics Letters, 38, 1496-1497. http://dx.doi.org/10.1049/el:20021089

[9] Motin, M.A., Hasan, M.I. and Asaduz-Zaman, M. (2012) Design and Optimization of a Low Cost Multi Band Microstrip Patch Antenna for K-Band, Ku-Band and X-Band Application. 15th International Conference on Computer and Information Technology (ICCIT), Chittagong, 22-24 December 2012, 615-620.

[10] Li, J.X., Shi, H.Y., Li, H. and Zhang, A.X. (2014) Quad-Band Probe-Fed Stacked Annular Patch Antenna for GNSS Applications. IEEE Antennas and Wireless Propagation Letters, 13, 372-375. http://dx.doi.org/10.1109/LAWP.2014.2306442

[11] Ahsan Ali, S., Rafique, U., Khan, A.U. and Arif, M. (2012) Multiband Microstrip Patch Antenna for Microwave Applications. IOSR Journal of Electronics and Communication Engineering, 3, 43-48. http://dx.doi.org/10.9790/2834-0354348

[12] Tulintseff, A.N., Ali, S.M. and Kong, J.A. (1991) Input Impedance of a Prob Fed Stacked Circular Microstrip Antenna. IEEE Transactions on Antennas and Propagation, 39, 381-390. http://dx.doi.org/10.1109/8.76338

[13] Jiri, S (1992) Analysis of Multilayer Microstrip Lines by a Conformal Mapping Method. IEEE Transactions on Microwave Theory and Techniques, 40, 769-772. http://dx.doi.org/10.1109/22.127530

[14] Bahal, I.J. and Bhartia, P. (1980) Microstrip Antennas. Artech House, Dedham.

[15] Deshmukh, A.A. and Kumar, G. (2007) Formulation of Resonant Frequency for Compact Rectangular Microstrip Antennas. Microwave and Optical Technology Letters, 49, 498-501. http://dx.doi.org/10.1002/mop.22161

[16] Garg, R. and Bahal, I.J. (1978) Microstrip Discountinuities. International Journal of Electronics, 45, 81-87. http://dx.doi.org/10.1080/00207217808900883

[17] Zhang, X.X. and Yang, F. (1998) Study of a Slit Cut Microstrip Antenna and Its Application. Microwave and Optical Technology Letters, 18, 297-300. http://dx.doi.org/10.1002/(SICI)1098-2760(199807)18:4<297::AID-MOP14>3.0.CO;2-1 
[18] Bahal, I.J. (2003) Lumped Elements for RF and Microwave Circuits. Artech House, Boston.

[19] Abboud, F., Damiano, J.P. and Papiernik, A. (1988) Simple Model for the Input Impedance of Coax-Fed Rectangular Microstrip Patch Antenna for CAD. IEE Proceedings H Microwaves, Antennas and Propagation, 135, 323-326. http://dx.doi.org/10.1049/ip-h-2.1988.0066

[20] Hoefer, J.R.W. (1997) Equivalent Series Inductivity of a Narrow Transverse Slit in Microstrip. IEEE Transactions on Microwave Theory and Techniques, 25, 822-824. http://dx.doi.org/10.1109/TMTT.1977.1129220 